

\title{
IBICT: Experiência brasileira em acesso aberto ao serviço de América Latina
}

\section{INTER VIEW}

\author{
Resumo \\ Entrevista a Bianca Amaro de Melo, Coordenadora do Laboratório de Metodologias de Tratamento e Disseminação da \\ Informação do Instituto Brasileiro de Informação em Ciência e Tecnologia - IBICT.
}

\section{Palavras-chave}

Bianca Amaro de Melo; Instituto Brasileiro de Informação em Ciência e Tecnologia; IBICT; Ciência; Tecnologia; Inovação; Brasil; América Latina; Entrevistas

\section{IBICT: Brazilian experience in open access to service of Latin America}

\section{Abstract Title}

Interview with Bianca Amaro de Melo, Coordinator of the Laboratory of Methodologies for Treatment and Dissemination of Information of the Brazilian Institute of Information in Science and Technology - IBICT.

Keywords Title

Bianca Amaro de Melo; Brazilian Institute of Information in Science and Technology; IBICT; Science; Technology; Innovation; Brazil; Latin America; Interviews 
Brasil é o país que atualmente lidera o maior nível desenvolvo econômico e social em América Latina. Entre as instituições finque deste desenvolvimento se encontra o Instituto Brasileiro de Informação em Ciência e Tecnologia - IBICT, o qual é responsável de produzir, integrar, documentar e socializar o conhecimento científico tecnológico de Brasil.

O IBICT foi pioneiro em Latinoamérica ao criar os primeiros cursos de documentação científica na década de 1950 e o mestrado em Ciências da Informação em 1970. Fundado em março de 1954, com o nome de Instituto Brasileiro de Bibliografia e Documentação (IBBD), o IBICT passou a ser chamado assim em 1976, com a missão de desenvolver uma rede de informação em Brasil. $O$ instituto é hoje referência na democratização do conhecimento, já que transfere, de forma gratuita, tecnologias que ampliam a oferta de informação científica em Internet. Graças a este esforço, Brasil é um dos principais países em número de registros digitais do mundo.

BIBLIOS conversou com Bianca Amaro de Melo, Coordenadora do Laboratório de Metodologias de Tratamento e Disseminação da Informação do IBICT a fim de conhecer detalhes das políticas de trabalho desta instituição.

\section{Qual é modelo atual de política de informação adotada pelo IBICT?}

Melo: Adotamos uma política que está relacionada com tudo o que é o movimento de acesso aberto. Em todo momento temos visto que todo mundo se estava preparando para este tipo de atuação. De fato a comunicação científica mudou. Vemos que temos hoje tecnologias que oferecem a oportunidade de trocar de uma maneira mais rápida a informação e assim acelerar o avanço do progresso da ciência. O IBICT ao ser um instituto de informação em ciência e tecnologia, começou a adotar todas as políticas e iniciativas inerentes do movimento do acesso aberto e graças a isso podemos construir pouco a pouco ações relacionadas a isso.

\section{Quais são os principais projetos que desenvolveu o IBICT sob esta política?}

Melo: Poderia citar primeiro à Biblioteca Digital de Tese e Dissertações. Começamos trabalhando a princípios do ano 2001 com quatro bibliotecas digitais em Brasil de diferentes instituições e fomos ao longo do tempo ampliando nossa relação. Hoje temos já 95 instituições de ensino e investigação que fazem parte desta grande biblioteca digital. Contamos com mais de 163, 500 tese a texto completo e disponível em acesso aberto. A ideia é continuar a ampliação para todas as universidades brasileiras, para que tenhamos um acervo de todas as teses e dissertações produzidas em Brasil. Este foi o primeiro passo que demos em direção ao acesso aberto.

O segundo passo foi trabalhar com o software de criação de revistas eletrônicas. Escolhemos o Open Journal Systems que é um software dedicado à gestão de revistas eletrônicas. Traduzimo-lo e adaptado. Temos também treinado a muitas universidades que tinham o interesse de criar suas revistas eletrônicas ou voltar suas revistas impressas em revistas eletrônicas. Este projeto foi todo um sucesso em Brasil porque as universidades tinham a necessidade de encontrar um veículo para expor sua produção. Hoje por hoje temos mais de 1300 revistas eletrônicas criadas com este software, começamos com treinamentos presenciais e já desenvolvemos também um treinamento a distância, assim seguiremos treinando aos interessados. Estamos agora também tratando a questão de qualidade destas revistas. Conquanto nossas capacitações se enfocam muito na comunicação científica, temos agora que cuidar um pouco mais do tema da qualidade destas revistas.

O terceiro tipo de atuação que tivemos foi a criação de repositórios institucionais. Inicialmente tínhamos pensado em trabalhar com repositórios temáticos, inclusive foi a primeira iniciativa do IBICT. Por aquele então, no ano 2003, começamos com o repositório de genética da Sociedade Brasileira de Genética. Mas me parece que o mundo e 
principalmente Brasil não estava tão preocupado na questão do acesso aberto à informação e esta iniciativa não teve o sucesso que esperávamos. Passado o tempo em todo mundo se começou a criar e desenvolver repositórios institucionais e o IBICT começou a trabalhar nesse sentido também. Por isso apresentamos um projeto à Financiadora de Estudos e Projetos de Brasil - FINEP e obtivemos um financiamento para a aquisição de equipes a fim de outorgar-se às universidades que desejavam implementar suas repositórios institucionais. Funcionou bastante bem, esta é minha avaliação, porque conseguimos implementar 39 repositórios até o momento, e desde outubro de 2010 já temos a disposição do público em acesso aberto, cerca de 45,000 documentos. Seguimos trabalhando em isso e nossa ideia também é que todas as universidades e institutos brasileiros tenham seus repositórios institucionais.

Além disso, o IBICT está promovendo um projeto de lei no Congresso Nacional de Brasil, o qual obrigaria a todas as universidades e institutos de investigação do país, o criar e depositar sua produção em repositórios, para que assim podamos saber qual é a real dimensão da produção científica brasileira. Seguimos com todas as atividades relacionadas com o acesso aberto, somos uma instituição pública, e se este é o caminho que já foi eleito por nossos pares nos países desenvolvidos, não temos que dizer nada, só temos que sair a ganhar com ações neste sentido.

\section{¿O IBICT conta com uma política de transferência destas experiências aos outros países da região?}

Melo: O IBICT tem a melhor das intenções de compartilhar com os demais países sua experiência. E me agradaria deixar bastante claro que nós não nos pomos no lugar de que somos melhores que os demais, não, mas já caminhamos algo e podemos poupar estes passos aos países que não passaram por determinadas coisas que já passamos. Então creio que nos pomos a disposição de nossos irmãos latino americanos para que eles aproveitem daquilo que já aprendemos como experiência. Eu tenho bastante claro que temos que unir esforços e ensinar ao mundo que embaixo da linha do equador, produz-se ciência de alta qualidade, e enquanto não nos ponhamos de acordo e juntemos nossos esforços ninguém se dará conta. Devemos começar a unir esforços entre nós, para que crescer como região e não como países isolados.

O IBICT se coloca a disposição para ajudar a todos quanto possamos, em aquilo que já temos experiência e que podemos compartilhar, estamos a sua disposição. Nosso sonho é que todos os países de América do Sul tenham seus repositórios, suas revistas de acesso aberto e que comecem a aparecer nos rankings muito bem posicionados; e que os países do norte comecem a olhar-nos com muito respeito e não com uma mirada assistencialista. Se nos juntamos eu creio que podemos fazer muitíssimo para o progresso e o avanço da ciência. O IBICT está a disposição de todos os países que requeiram ou precisem de nossa ajuda.

\section{Bibliografia}

IBICT. BDTD [em línea]: Biblioteca Digital Brasileira de Teses e Dissertações. Brasília: Brasil, Instituto Brasileiro de Informação em Ciência e Tecnologia, 2011 [fecha de consulta: 30 Março 2012]. Disponível em: http://bdtd. ibict.br/

IBICT. RIDI [em línea]: Repositório Institucional do IBICT. Brasília: Brasil, Instituto Brasileiro de Informação em Ciência e Tecnologia, 2011 [fecha de consulta: 30 Março 2012].

Disponível em: http://repositorio.ibict.br/

IBICT. SEER [em línea]: Sistema de Eletrônico de Editoração de Revistas. Brasília: Brasil, Instituto Brasileiro de Informação em Ciência e Tecnologia, 2011 [fecha de consulta: 30 Março 2012]. Disponível em: http://seer.ibict.br/ 
Biblios Brazilian experience in open access to service of Latin America

\section{Produção}

Transcrição: Julio Santillán-Aldana

Edição: Michelli Pereira da Costa

\section{Agradecimento}

Pontificia Universidad Católica del Perú. Especialidad de Ciencia de la Información.

Instituto Brasileiro de Informação em Ciência e Tecnologia 